\title{
Analysis of the influence of pile embedded cap depth on horizontal bearing capacity of PHC pipe pile group with cap
}

\author{
Xue Bai ${ }^{1}$, Guohong Zeng*, Zhaosheng Guo ${ }^{1}$ \\ ${ }^{1}$ Civil Engineering College, Taiyuan University of Technology, Taiyuan, Shanxi,030024, China
}

\begin{abstract}
This paper is based on the background of the field experiment of the closed renovation project of the coal yard of Shanxi Zhangshan Power Generation Co., Ltd., and the horizontal bearing capacity experiment of the three-pile cap foundation of the in-line PHC pipe piles to be carried out on the site is used as the prototype. ABAQUS establishes an analysis model to analyze the influence of pile embedded cap depth on the horizontal bearing capacity of pile cap foundation. The results show that the maximum bending moment the pile can withstand increases as the depth of the pile embedded cap increases. Therefore, increasing the depth of the embedded cap can increase the horizontal bearing capacity of the three-pill.
\end{abstract}

\section{Introduction}

Compared with ordinary concrete piles, pre-stressed highstrength concrete pipe piles (PHC pipe piles) have many advantages such as high strength, controllable quality, quick construction and less pollution to the surrounding environment. In recent years, it has developed rapidly in China. The manufacturing process level of PHC pipe piles has also been rapidly improved with its application in engineering practice. In general engineering, PHC pipe piles are used to strengthen the foundation and improve the bearing capacity of the foundation. In most cases, the foundation structure with PHC pipe piles as a component of the pile foundation mainly bears the upper axial load. However, in the bank slopes, high-rise buildings, electrical towers, ports, long-span bridges and other projects, the pile foundation still bears a lot of The large horizontal load makes the section of the connecting part of the pile cap in a state of compression-bending-shear or tension-bending-shearing force, which is easy to cause shear failure and compression-bending failure of the pile body ${ }^{[1,2,3]}$. Therefore, studying the bearing capacity of rigid pile foundations under horizontal loads has important engineering value. Sheppard proposed eight structural forms of pile-cap connection in 1983, of which A, B, C and $\mathrm{D}$ are prefabricated pile heads deeply embedded to improve the strength of the pile-cap connection. Zhuang Zhouyi, Zhou, Huang Haiyun and others did field experiments to study the static test of the PHC pipe pilesoil interaction performance, and gave the horizontal displacement along the pile depth and the bending moment distribution along the pile depth ${ }^{[4]}$. Song Xiuguang and Yue Hongya used finite element numerical simulation software to analyze the horizontal load-bearing characteristics of pile groups and soil when the moment between piles of the double-pile cap foundation changes ${ }^{[5]}$. When the horizontal load is constant, the maximum bending moment of the front pile is obviously larger than that of the rear pile, and the zero point of the pile body shear force of the front pile is obviously larger than that of the rear pile. Ma Chenglong He Wubin and others have done large-scale field experiments to study the influence of different arrangements on the horizontal bearing capacity of pile groups. The results show that the horizontal load capacity of pile groups is significantly higher than the horizontal load capacity of single piles. The arranged three-pile cap foundation can fully exert the horizontal bearing capacity of the pile group, and the load on the front pile is slightly larger than that of the rear pile. The research team led by Guo Zhaosheng and He Wubin analyzed the improvement of the horizontal bearing capacity of pile caps by different pile-cap node structures and strengthening measures through model experiments and numerical simulations ${ }^{[6-7]}$. In the engineering of pile cap foundation, there are many strengthening measures for the pile-cap connection. Due to the high cost of the pilecap experiment, there is a lot of research on the effect of pile embedded cap depth on the horizontal bearing performance of the pile-cap connection. Relatively few related numerical simulations, so this paper uses ABAQUS finite element software to establish a pile-capsoil interaction model to simulate the effect of different pile embedded cap depths on the in-line three-pile PHC pipe pile-support Strengthen the horizontal bearing.

Capacity of the platform foundation and verify the rationality of the modelling ${ }^{[8-9]}$.

\section{Model construction design value}

PHC pipe piles use the design values of PHC600-AB 130 pipe piles in the National Building Standard Design Atlas

*Corresponding author's e-mail: 1145235608@qq.com 
10G409, the pile body concrete grade is C80, the standard value of compressive strength is $f_{c k}=50.2 \mathrm{MPa}$, and the design value of compressive strength $f_{c}=35.9 \mathrm{MPa}$; The standard value of tensile strength $f_{t k}=3.11 \mathrm{MPa}$. the design value of tensile strength $f_{t}=2.22 \mathrm{MPa}$; the main reinforcement is $16 \varnothing 10.7$ prestressed rods. the standard value of ultimate strength is $f_{p t k}=1420 \mathrm{MPa}$; the spiral stirrup is $\emptyset^{b} 5 @$ The diameter of the distribution circle of cold drawn low carbon steel wire is $253 \mathrm{~mm}$, and the standard value of ultimate strength $f_{p t k}=600 \mathrm{MPa}$. A concrete core with a strength of $\mathrm{C} 30$ is set up at the junction of the PHC pipe pile and the cap, and the length is 1.8 meters. The initial length of the simulated pile length is 10 meters, and the depth increment of the embedded cap is $100 \mathrm{~mm}$. The pile end steel gasket is Q235 steel with a thickness of $20 \mathrm{~mm}$. A $120 \times 50 \times 12 \mathrm{~mm}^{3}$ Q235 steel connecting plate is used for the pile end anchoring steel bar, and the initial length of the anchoring steel bar is 700 $\mathrm{mm}$. With the increase of the pile embedding depth, the anchoring steel bar and the embedding depth increment will decrease by the same amount ${ }^{[1-2]}$.

The concrete of the cap is C30 concrete with a size of $1.2 \times 5.2 \times 0.9$ meters. The reinforcement of the cap has little effect on the horizontal bearing capacity of the PHC pipe pile, so the cap is not reinforced.

A layer of soil is selected as the simulated soil, and the elastoplastic theory of Mohr-Coulomb is selected. Its modulus is $30 \mathrm{MPa}$, Poisson's ratio is 0.2 , internal friction angle is $20^{\circ}$, expansion angle is $10^{\circ}$, and size is $18 \times 21.6$ $\times 22 \mathrm{~m}^{3}$. The influence of groundwater is not considered.

\subsection{Establishment of finite element ABAQUS software model}

C3D8R elements are used for the cap, PHC pipe pile, core filling, and soil. The constitutive structure of concrete adopts the plastic damage model. The constitutive relationship diagram is as follows (Table 1, Table 2) :

The pile end steel gasket also uses C3D8R unit. The prestressed steel bars, spiral stirrups and anchoring steel bars adopt truss elements (T3D2). The constitutive relationship is a two-fold line model with five stiffness degradation. Reinforced skeleton is embedded (EMBED) in concrete. The steel gasket and the pile body and the anchoring steel bar and the steel gasket are bound by (TIE) binding constraints. The type of contact between concrete and soil is face-to-face contact. The contact attribute between the pile side pand the soil and the cap and the soil is tangential "penalty" friction. The normal direction

Table 1 Concrete material simulation parameters

\begin{tabular}{|c|l|l|l|l|l|l|}
\hline Concrete & $\begin{array}{l}\text { Elastic } \\
\text { Modulus/MPa }\end{array}$ & $\begin{array}{l}\text { Density } \\
/\left(\mathrm{kg} / \mathrm{m}^{\wedge} 3\right)\end{array}$ & $\begin{array}{l}\text { Poisson's } \\
\text { ratio }\end{array}$ & $\begin{array}{l}\text { Expansion } \\
\text { angle }\end{array}$ & $\begin{array}{l}f_{b 0} \\
/ f_{c 0}\end{array}$ & $\mathrm{k}$ \\
\hline$C_{30}$ & 29400 & 2400 & 0.3 & 38 & 1.16 & $2 / 3$ \\
\hline$C_{80}$ & 38000 & 2800 & 0.3 & 38 & 1.16 & $2 / 3$ \\
\hline
\end{tabular}

Table 2 Soil material simulation parameters

\begin{tabular}{|l|l|l|l|l|l|}
\hline Material & $\begin{array}{l}\text { Density } \\
/\left(\mathrm{kg} / \mathrm{m}^{\wedge} 3\right)\end{array}$ & $\begin{array}{l}\text { Poisson's } \\
\text { ratio }\end{array}$ & $\begin{array}{l}\text { Elastic } \\
\text { Modulus/MPa }\end{array}$ & $\begin{array}{l}\text { Friction } \\
\text { angle } \\
{ }^{\circ}\end{array}$ & $\begin{array}{l}\text { Expansion } \\
\text { angle } \\
{ }^{\circ}\end{array}$ \\
\hline Soil & 1900 & 0.3 & 30 & 20 & 10 \\
\hline
\end{tabular}

is hard contact, and the friction coefficient is 0.25 . It is in hard contact with the cap. The first step of the analysis step is to balance the ground stress, the second step is to apply contact and boundary conditions, the third step is to apply a vertical load, and the fourth step is to apply a load to the model by applying a horizontal displacement, and the amplitude (AMP) is used at the same time. Graded application of loads.

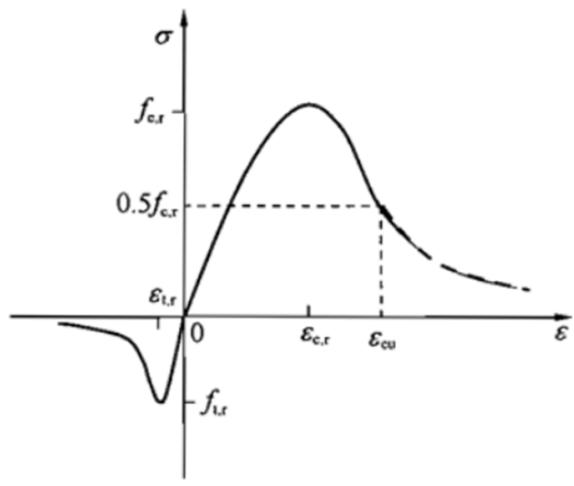

Fig.1. Full stress-strain curve of concrete under tension and compression

\subsection{Depth of pile embedded cap and load condition}

This paper studies the influence of PHC pipe pile embedded cap depth on the horizontal bearing capacity of pile-cap. With the change of pile embedding cap depth, 4 sets of simulated working conditions are designed, and the embedded depth increment is $100 \mathrm{~mm}$. The applied constant vertical axial compression is $0.2 \mathrm{MPa}$, which is $1 / 8$ of the design value of PHC pipe pile concrete axial compression, which is less than 0.3 of the limits specified in GB50010-2010 "Specification for Design of Concrete Structures". By changing the depth of pile embedded cap to study the influence of pile embedded depth on the horizontal bearing capacity of $1 \times 3$ PHC pipe pile group piles. The simulation conditions are shown in Table 1.

Table 3 Simulation working conditions of $1 \times 3$ type cap-PHC pipe pile group pile foundation

\begin{tabular}{|c|l|l|l|l|}
\hline model & M-100 & M-200 & M-300 & M-400 \\
\hline $\begin{array}{c}\text { Pile embedded cap } \\
\text { depth /mm }\end{array}$ & 100 & 200 & 300 & 400 \\
\hline $\begin{array}{c}\text { Axial } \\
\text { pressure/MPa }\end{array}$ & 0.2 & 0.2 & 0.2 & 0.2 \\
\hline
\end{tabular}

\section{Calculation results and analysis}

\subsection{Analysis of internal force and displacement of PHC pipe pile}

In the simulation, the depth of the PHC pipe piles of the four groups of models into the soil is the same as 9.95 meters, and the simulated thickness of the soil is 21.6 meters, which is twice the maximum pile length. The 
simulation results analyzed the bending moment of the front pile (close to the horizontal load) and the earth pressure in contact with the soil in the $1 \times 3$ type cap-PHC pipe pile group pile model.

It can be seen from Figure 2:(1) With the increase of the depth of the pile embedded cap, the pile tip bending moment decreases first and then increases. When the PHC pipe pile embeds the cap depth of $300 \mathrm{~mm}$, the pile tip bending moment is the smallest. It can be inferred that the bending moment of the pile end increases with the depth of the pile end embedded in the cap, and its minimum is between $200-400 \mathrm{~mm}$. The smaller the bending moment of the pile end, the smaller the maximum tensile stress on the pile end section, and the less easy the pile end is damaged. (2) As the depth of pile embedded cap increases, the maximum bending moment of the pile body first decreases and then increases. In addition, the position of the zero point of the bending moment and the maximum bending moment are gradually moved downwards, so that the distribution range of the earth pressure against the deformation of the pile body increases, and the load shared by the soil body increases, which can greatly reduce the overall lateral displacement of the structure. (3) From the knowledge of material mechanics, it can be known that the maximum value of the bending moment is the zero point of shear force, so the zero point of shear force moves down with the downward movement of the zero point of bending moment, because the earth pressure distribution area moves downward. The zero point of the bending moment is the inflection point of the deflection-displacement curve, which is the slope of the pile section angle-displacement function. When the pile tip displacement is the same, the more the inflection point of the pile deflection curve moves downward, the smaller the pile rotation angle at the inflection point is. The greater the stiffness ${ }^{[10,11,12,13]}$. Conversely, for the same pile section corner, the greater the corresponding pile tip displacement, the greater the lateral load that the pile can bear, and the greater the bending and shear resistance of the pile. The simulated bending moment diagram is very similar to the simulation results of Song Xiuguang and Yue Hongya.

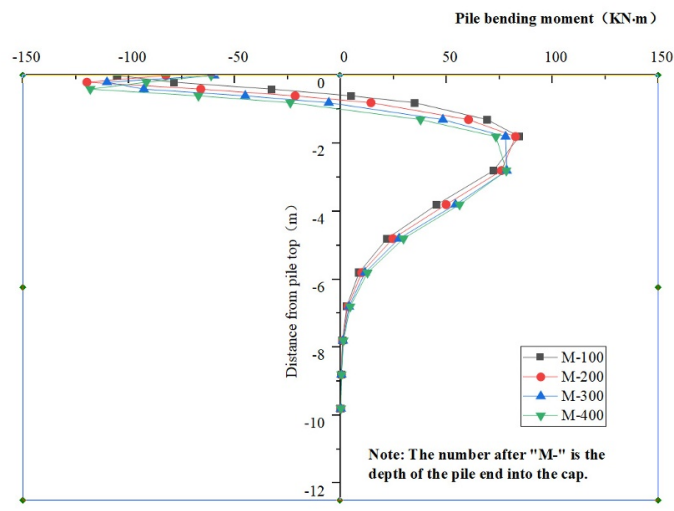

Fig.2. Pile body bending moment distribution diagram

\subsection{Analysis of the passive earth pressure on the side of the front pile}

It can be seen from Fig. 3 that the downward distribution law of the passive earth pressure on the side of the front pile first decreases and then increases, but there is no reverse pressure. According to Fig. 4, it can be seen that the pile displacement is about 3 meters away from the upper surface of the soil. The sudden change in the growth rate of the pile leads to an extremely reduced compression of the soil. The soil pressure on the side of the pile and the horizontal displacement of the pile body in the 4 groups of working conditions are very similar. It can be seen that the depth of the pile embedded cap has no significant influence on the size and distribution depth of the soil pressure.

It can be seen from the above simulation results as follows: (1) the depth of PHC pipe piles embedded in the cap has a certain effect on the horizontal bearing capacity of PHC pipe pile groups with caps. The depth of the PHC pipe pile embedded in the platform will affect the relative size of the maximum bending moment of the pile end and the pile body. As the depth of the PHC pipe pile embedded in the platform increases, the maximum bending moment of the pile end gradually increases, and the maximum bending moment of the pile body gradually decreases. The simulation results show that the maximum bending moment of the pile body and the maximum bending moment of the pile end change with the increase of the depth of the pile end embedded in the cap. When the maximum bending moment of the pile body is equal to the maximum bending moment of the pile end, under the same load The maximum bending moment the pile bears is the smallest, and the pile is not easy to be destroyed. (2) The change in the depth of the pile embedded cap has a greater impact on the horizontal plastic distribution area of the soil near the contact between the pile and the soil. As the depth of the pile embedded cap increases, the pile end restraint becomes better and better. The support constraint becomes an approximate solid end constraint.

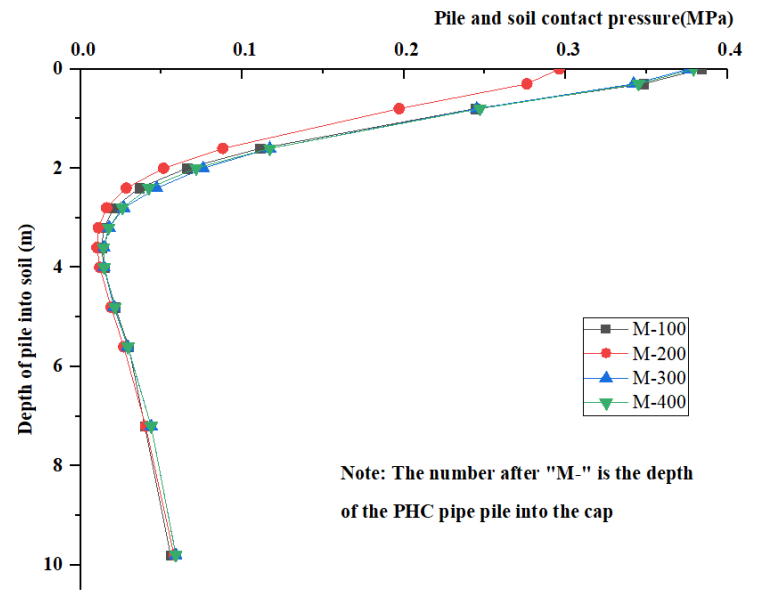

Fig. 3. Front pile and soil contact pressure distribution

It can be seen from the changing law of the bending moment that the pile end constraint is the optimal semirigid constraint when the pile embedded depth reaches about $300 \mathrm{~mm}$. Therefore, the semi-rigid constraint is a pile-cap connection Node optimal constraint form. (3) 
According to the simulation results, the soil pressure distribution cloud diagram and the soil pressure distribution function diagram, the depth of the pile embedded cap has no obvious effect on the soil pressure distribution of the pile body, but it has a greater impact on the distribution range of the soil pressure below the pile bottom.

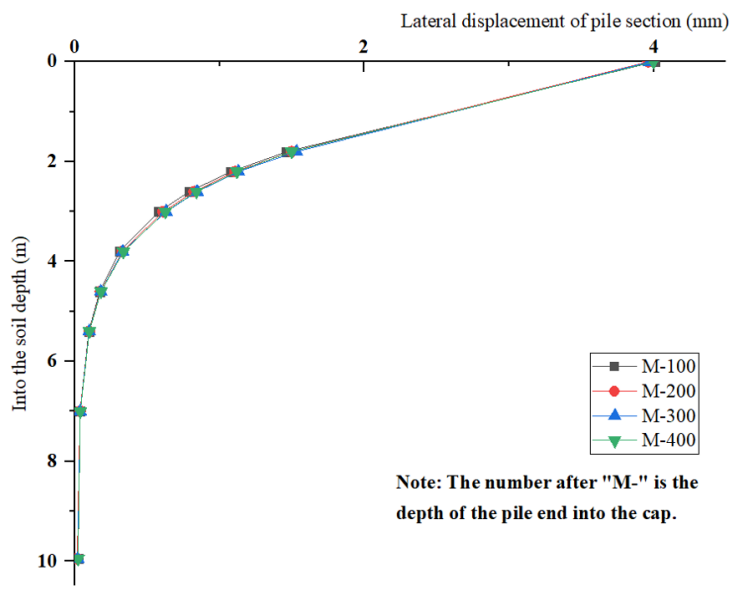

Fig.4. Distribution of pile side soil pressure along pile depth

Simulation shortcomings: due to the small number of selected simulation conditions and the large increase in the embedded depth, the maximum bending moment of the pile body is not clearly displayed in the bending moment diagram. The law highlighted by the simulation results is also not obvious. In the follow-up work, the horizontal bearing performance of the PHC pipe pile group with cap will be analyzed from other factors.

\section{References}

1. Specification for Building Pile Foundation [S]. Beijing: China Building Industry Press, 2008: 33. JGJ94-2008, Technical.

2. 10SG409, Atlas of prestressed concrete pipe piles [S]. Beijing: China Planning Press, 2010.
3. Sheppard DA, Seismic design of prestress concrete piling [J]. PCI Journal, 1983, 28 (2): 20-49.

4. Zhuang Yizho u, Huang Haiyun, Qian Haimin et al. Pseudo-static test of PHC pipe pile-soil interaction performance $[\mathrm{J}]$. China Journal of Highway and Transport, 2017, 30 (04): 42-51+71.

5. Song Xiuguang, Yue Hongya, Zhou Zhidong, Zhuang Peizhi, Zhang Hongbo. Numerical simulation study on horizontal bearing characteristics of pile groups. [J]. Railway Construction, 2015 (8): 1003-1995

6. Guo Zhaosheng, He Wubin, Bai Xiaohong.The pseudo-static model test of pile-cap-soil composite bearing body[J]. Rock and Soil Mechanics, 2018, 39 (09): 3321-3330.

7. The simulated bending moment diagram is very similar to the simulation results of Song Xiuguang and Yue Hongya. 8. Zhu Xiangrong, Wang Jin chang. Introduction to some soil models in ABAQUS software and their engineering application $[\mathrm{J}]$. Rock and Soil Mechanics, 2004, S2: 144-148.

9. The simulated bending moment diagram is very similar to the simulation results of Song Xiuguang and Yue Hongya.

10. The simulated bending moment diagram is very similar to the simulation results of Song Xiuguang and Yue Hongya.

11. Wang Tiecheng, Yang Zhijian, Zhao Hailong et al. Experimental research and finite element analysis of PHC pipe pile and cap connection node [J]. Journal of Tianjin University (Natural Science and Engineering Technology)

12. The simulated bending moment diagram is very similar to the simulation results of Song Xiuguang and Yue Hongya.

13. Guo Zhenhai. The strength and constitutive relationship of concrete-principle and application[M]. Beijing: China Construction Industry Press, 2006: 1372 . 